\title{
Influence of Gradation on the Mechanical Properties of Aged Hot-Mix Asphalts
}

\author{
Saieth Baudilio Chaves-Pabón ${ }^{1}$, Hugo Alexander Rondón-Quintana ${ }^{2}$ (D) and Carlos Alfonso Zafra-Mejía ${ }^{2, *(D)}$ \\ 1 Programa de Ingeniería Civil, Facultad de Estudios a Distancia, Universidad Militar Nueva Granada, \\ Cajicá 250240, Colombia; saieth.chaves@unimiltar.edu.co \\ 2 Facultad del Medio Ambiente y Recursos Naturales, Universidad Distrital Francisco José de Caldas, \\ Bogotá 111611, Colombia; harondonq@udistrital.edu.co \\ * Correspondence: czafra@udistrital.edu.co
}

check for updates

Citation: Chaves-Pabón, S.B.; Rondón-Quintana, H.A.; Zafra-Mejía, C.A. Influence of Gradation on the Mechanical Properties of Aged Hot-Mix Asphalts. Buildings 2021, 11, 632. https://doi.org/10.3390/ buildings 11120632

Academic Editor: Oldrich Sucharda

Received: 18 November 2021

Accepted: 7 December 2021

Published: 10 December 2021

Publisher's Note: MDPI stays neutral with regard to jurisdictional claims in published maps and institutional affiliations.

Copyright: (c) 2021 by the authors. Licensee MDPI, Basel, Switzerland. This article is an open access article distributed under the terms and conditions of the Creative Commons Attribution (CC BY) license (https:// creativecommons.org/licenses/by/ $4.0 /)$.

\begin{abstract}
When a hot-mix asphalt (HMA) ages, its mechanical properties, resistance, and durability change. Several studies have been conducted throughout the world to evaluate the effects of aging in HMAs. However, few studies have analyzed the influence of gradation. The main objective of this study was to evaluate the influence of gradation on the mechanical properties of aged HMA mixes. For such purposes, three HMA mixes with different gradations were manufactured (named HMA-10, HMA-19, and HMA-25), which were conditioned in STOA (short-term oven aging) and LTOA (long-term oven aging) by following the guidelines established by the AASHTO R30 specification. Marshall, Indirect Tensile Strength (ITS), resilient modulus, permanent deformation, fatigue (under controlled-stress condition), and Cantabro tests were performed. These tests were carried out to evaluate resistance under monotonic and cyclic load as well as the resistance to moisture damage and abrasion. The best performing mix in the test was HMA-19. There is no clear trend about the influence of gradation over the susceptibility of mixes for aging. This susceptibility changes depending on the test performed and the property measured. Furthermore, in resilient modulus tests, it is observed that the influence of gradation on aging susceptibility changes depending on the test temperature.
\end{abstract}

Keywords: aging; hot-mix asphalt; gradation; STOA; LTOA

\section{Introduction}

A great portion of roadways throughout the world are built with asphalt pavements. In turn, these roadway structures generally use hot-mix asphalts (HMA) to comprise the asphalt layer. When manufacturing HMAs in asphalt plants, their components (asphalt binder and aggregates) are exposed to high temperatures. Likewise, these mixes must be transported to construction works and then extended and compacted at high temperatures. During this stage, asphalt binder thermally oxidizes, volatilizes its light components, rearranges its microstructure, and changes its physical-chemical properties (aging) [1] This aging process is named "short-term". Posteriorly, HMA is exposed during the useful service life of asphalt pavement to the effects of weather (mainly photooxidation caused by sunlight and ultraviolet radiation, temperature changes, moisture, and evaporation, among others) as well as traffic. During this stage, asphalt continues to oxidize and age. This aging process is named "long term" [2-4]. According to [5,6], changes in micro-mechanical properties, adhesion properties, and chemical properties are more significant in the long term than in the short term. The problem that occurs when asphalt ages is that it becomes fragile, brittle, and loses its capacity to adhere to the aggregate and to make mixes cohesive, contributing to the appearing of early distresses in asphalt layers (e.g., thermal cracking and cracking due to load fatigue, top-down type cracking (TDC), raveling, stripping and potholes, among others). This reduces pavement's durability and increases maintenance and repair costs. As a result of this, it is important to conduct studies on this topic. 
Throughout the world, several research efforts have been conducted to evaluate the effects of aging over the mechanical properties of asphalt binders and asphalt mixes. Some have been more limited than others; however, all of them are inclined to continue deepening the discussion around the topic. Complete states of knowledge that are useful as background can be consulted in [1,4,7-9]. A great portion of these studies have focused on modifying or improving asphalt binder properties (using polymers, additives, and rejuvenating agents of adherence enhancers, among others) [10-13]. On several occasions, some of these studies forget that HMAs are materials, whose properties depend on the interaction between asphalt binder-aggregate. Additionally, they forget that within this interaction, the aggregate's gradation plays an important role upon the volumetric properties and mechanical performance of the mix [14-16]. For all the above, the main objective of this study was to evaluate the influence of gradation on the mechanical properties of an HMA mixture.

Few studies have focused on evaluating the influence of gradation within the phenomenon of aging in HMA mixes. Furthermore, some only evaluate a given particular property, with limited experimental designs. In contrast to other studies conducted on the topic, this study designed a more complete experimental phase to evaluate the change in mechanical properties that three HMA mixes with different gradations undergo when they age. Additionally, aspects associated to mix durability were evaluated, which have been little studied. Durability is understood as the long-term capacity that a material has for resisting climate changes, aging, and the abrasive action of traffic [17,18]. Tests for resistance under monotonic load (Marshall, Indirect Tensile Strength (ITS)) and cyclic load (resilient modulus, permanent deformation, and fatigue) were conducted on an unaged mix (named control mix), a short-term aged mix (STOA, Short-Term Oven Aging), and a long-term aged mix (LTOA, Long-Term Oven Aging). Additionally, tests with the purpose of evaluating moisture damage resistance (using the TSR resistance parameter, Tensile Strength Ratio) and (Cantabro) abrasion wear were used. An ANOVA variance analysis was conducted with a reliability level of $95 \%$ to evaluate if the properties measured on mixes presented statistically significant changes when they age in STOA and LTOA.

There are multiple techniques for simulating short-term and long-term aging $[1,7]$. For the case of HMAs, the most used techniques for these purposes are standardized STOA and LTOA procedures, respectively. These techniques were proposed in AASHTO R30 [19], which are based on the studies carried out by $[20,21]$. In theory, LTOA simulates the aging of a mix between 7 and 10 years of service [8]. These procedures were conducted in this study to simulate aging in the HMA mixes.

\section{Experimental Procedure}

\subsection{Materials}

The aggregate presents the following properties: specific gravity and absorption of the coarse fraction [22] $=2.63$ and $1.4 \%$, respectively; specific gravity and absorption of the fine fraction [23] = 2.54 and 1.7\%, respectively; abrasion and impact in the Los Angeles Machine at 500 revolutions [24] $=22.2 \%$; abrasion in the Micro-Deval apparatus [25] $=20.7 \%$; fracture resistance using the method of $10 \%$ fine particles [26] $=135 \mathrm{kN}$; percentage of fractured particles in coarse aggregate [27] $=91 \%$ (one face) and $86 \%$ (two faces); soundness of aggregate by use of magnesium sulfate [28] = 11\%; plasticity index [29] = no plastic; lastly, flat and elongated particles in coarse aggregate [30] $=7.1 \%$ and $4.0 \%$, respectively.

Asphalt cement (AC) is an AC $60 / 70\left(65.2 \mathrm{~mm} / 10\right.$ of penetration at $25^{\circ} \mathrm{C}, 100 \mathrm{~g}$, $5 \mathrm{~s}-[31])$ that presents a softening point $[32]=51.1^{\circ} \mathrm{C}$, penetration index [33] $=-0.28$, specific gravity [34] $=1.010$, and ductility $\left(25^{\circ} \mathrm{C}, 5 \mathrm{~cm} / \mathrm{min}-[35]\right)>105 \mathrm{~cm}$. After RTFOT (Rolling Thin Film Oven Test [36]), the properties of AC 60/70 were as follows: mass loss $=0.36 \%$, penetration $=51 \mathrm{~mm} / 10$, softening point $=55.3^{\circ} \mathrm{C}$, specific gravity $=1.018$, and ductility $=78 \mathrm{~cm}$. After RTFOT + PAV (Pressure Aging Vessel [37]), the properties of AC $60 / 70$ were as follows: penetration $=32.7 \mathrm{~mm} / 10$, softening point $=59.8^{\circ} \mathrm{C}$ and specific gravity $=1.030$. Viscosity curves (Figure 1) of the unaged AC 60/70 (control) and 
the one subjected to aging processes in RTFOT and RTFOT + PAV were measured by using a Rotational Viscometer [38].

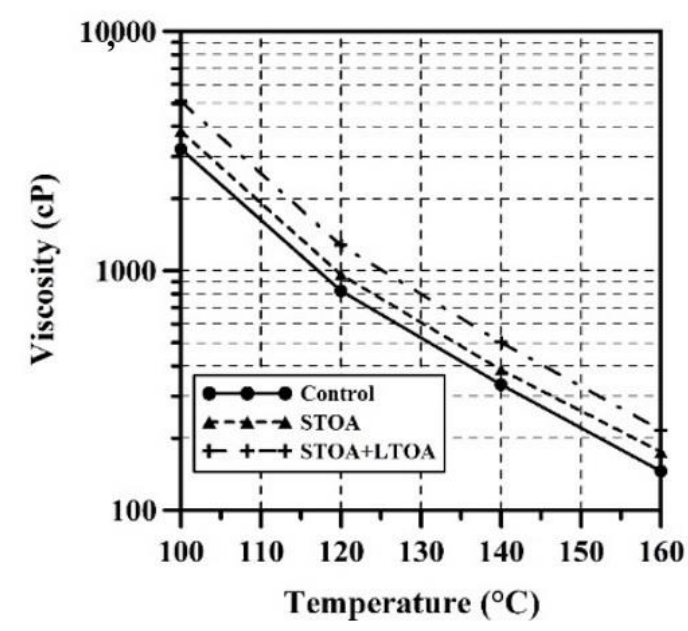

Figure 1. Viscosity curves of unaged AC 60/70 (control) and mixes subjected to aging in RTFOT and RTFOT + PAV.

In an obvious manner, asphalt binder stiffness increased when exposed to aging processes of RTFOT and RTFOT + PAV (softening point and viscosity increased, and penetration and ductility decreased). These physical changes are coherent to those that are widely reported by other researchers [2,9,39-41]. Additionally, specific gravity increased mainly because during aging, asphalt binders tend to increase their molecular weight [42] and its LMS (large molecular size) $[5,41,43,44]$.

\subsection{Gradations of HMAs}

Three gradations were used according to [45] to manufacture mixes (Figure 2): HMA10, HMA-19, and HMA-25 (the number indicates the maximum particle size in $\mathrm{mm}$ ). HMA-10 is recommended for comprising surface layers with a compact thickness between 3 and $4 \mathrm{~mm}$; HMA-19 is recommended for surface layers and asphalt concrete base course with a compact thickness superior to $4 \mathrm{~cm}$; and HMA-25 is recommended for asphalt concrete base course with a compact thickness greater than $7.5 \mathrm{~cm}$ [45].

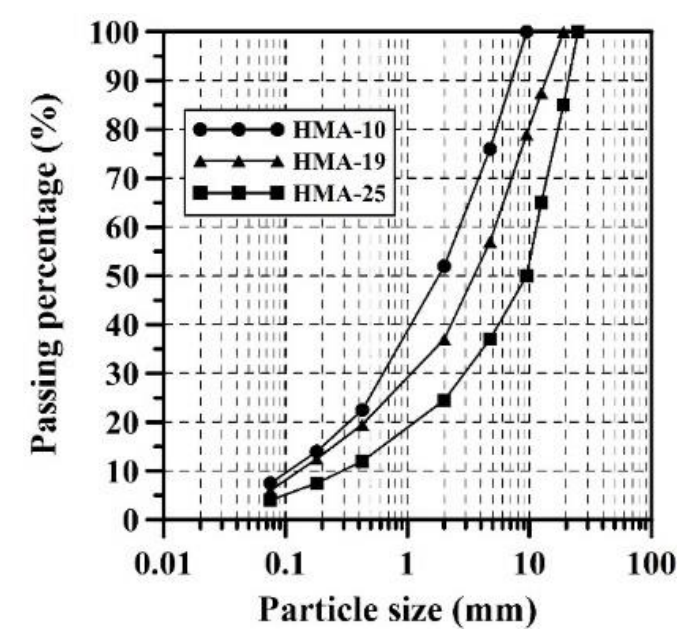

Figure 2. Particle size distribution curves (gradations) of HMAs. 


\subsection{HMA Designs}

Control mixes (unaged) were designed using the Marshall method [46] and following the criteria established by [45]. The Marshall type cylindric samples $(63.5 \mathrm{~mm} \times 101.6 \mathrm{~mm})$ of $1200 \mathrm{~g}$ of mass were manufactured considering the gradations that are shown in Figure 2. The dosing of samples was carried out by mass, and asphalt cement percentages varying between 4.0 and $6.0 \%$ were used. To manufacture samples, the mix temperature (MT) was of $150{ }^{\circ} \mathrm{C}$. Compaction was carried out at a temperature (CT) of $145^{\circ} \mathrm{C}$, applying 75 blows per face. MT and CT were obtained based on the viscosity results of control AC $60 / 70$ (Figure 1). Each parameter measured (air void content-AV, voids in the mineral aggregate-VMA, voids filled with asphalt-VFA, stability-S, flow-F, and S/F ratio) was obtained by averaging the results of testing 5 samples. $S$ and $F$ were obtained by subjecting samples to a temperature of $60^{\circ} \mathrm{C}$ under a monotonic load with a speed of $50.8 \mathrm{~mm} /$ minute in a Marshall compression machine. The optimal asphalt content (OAC) was of 5.8, 5.3, and 4.5\% for HMA-10, HMA-19, and HMA-25 mixes, respectively. This $\mathrm{OAC}$ was the one used in posterior project stages to manufacture samples.

\subsection{Short-Term (STOA) and Long-Term (LTOA) Aging Simulation}

Using OAC values, new Marshall samples for each type of unaged mix are manufactured (these are named control mix), which are aged under STOA and LTOA procedures. To simulate these aging processes, AASHTO R30 guidelines [19] were followed. To conduct the STOA process, the asphalt mix in a loose state is subjected to $135^{\circ} \mathrm{C}$ in an oven for $4 \mathrm{~h}$ and then compacted by applying 75 blows per face. To simulate LTOA aging, initially, each sample was exposed to the same STOA process described above, to then be subjected to a temperature of $85^{\circ} \mathrm{C}$ in an oven for 5 days.

\subsection{Marshall and ITS Tests}

Marshall [46] and Indirect Tensile Strength (ITS [47]) tests were performed on the following mixes: HMA-10, HMA-19, and HMA-25 (control, STOA, and LTOA). Each Marshall test parameter (S, F, S/F, AV and VFA) was calculated by averaging the results obtained on the three samples. On another hand, the ITS test is generally performed on samples manufactured with an AV of $7 \pm 0.5 \%$. However, this study evaluated the ITS on samples that were manufactured based on their AVs obtained by design. Three conditioned specimens (ITSC) were failed by type of mix analyzed and three other under unconditioned specimens (ITSU). With the results obtained, moisture damage resistance was calculated and evaluated using the TSR ratio (Tensile Strength Ratio, in percentage $)=($ ITSC $/$ ITSU $) \times 100$. ITSU and ITSC were obtained by subjecting samples to a monotonic load with a velocity of $50 \mathrm{~mm} / \mathrm{min}$ in the Marshall compression machine. The test temperature for ITS tests was $25^{\circ} \mathrm{C}$.

\subsection{Resilient Modulus, Permanent Deformation, and Fatigue Resistance}

The stress-strain relationship of each HMA (control, STOA, and LTOA) was characterized through resilient modulus (RM) tests [48]. This test was carried out in a Nottingham Asphalt Tester (NAT). The "half-sine" load type was applied under frequencies of $2.5 \mathrm{~Hz}$ (load application time- $\mathrm{tc}=125 \mathrm{~ms}$ and recess period- $\mathrm{tr}=275 \mathrm{~ms}$ ), $5.0 \mathrm{~Hz}$ ( $\mathrm{tc}=63 \mathrm{~ms}$ and $\operatorname{tr}=137 \mathrm{~ms}$ ), and $10 \mathrm{~Hz}$ (tc $=31 \mathrm{~ms}$ and $\mathrm{tr}=69 \mathrm{~ms}$ ). A Poisson ratio of 0.35 was assumed to determine the RM. Test temperatures were 10, 20, and $30^{\circ} \mathrm{C}$. Each RM was determined based on the average of results obtained on the three samples.

Permanent deformation resistance tests were carried out in the NAT by following the guidelines established by the UNE-EN 12697-25 specification [49]. The accumulation of permanent deformation was measured on samples subjected to $40^{\circ} \mathrm{C}$. When samples reached this temperature inside the NAT, 600 cycles of preload $(10 \mathrm{kPa})$ were applied for $20 \mathrm{~min}$. Posteriorly, 3600 load cycles under a stress of $100 \mathrm{kPa}$ were applied. In each load cycle, the vertical displacement that occurred on the sample was measured by using LVDTs (Linear Variable Differential Transformers). Load cycles were square wave type with a 
frequency of $0.5 \mathrm{~Hz}$ ( $1 \mathrm{~s}$ of load application and $1 \mathrm{~s}$ of rest per cycle). Each permanent deformation curve was determined by averaging the results obtained on the three samples.

Fatigue resistance was also measured in the NAT by following the guidelines established in the UNE-EN 12697-24 specification [50]. The indirect tensile load mode was controlled stress. The test temperature and load frequency were $20^{\circ} \mathrm{C}$ and $10 \mathrm{~Hz}$, respectively. The failure criterion was used to capture the number of cycles in which the sample's total rupture was obtained $\left(N_{f}\right)$. Each fatigue curve was determined based on the results obtained when failing a minimum number of nine samples.

\subsection{Cantabro Test}

This test is mainly carried out on open-graded type mixes. However, during the last few years, it has been used to provide information regarding aspects associated to durability in dense-graded type mixes such as HMA [51,52]. The percent of weight loss (Cantabro Loss (CL)) in each sample was estimated through a relationship between mass lost in the test after applying cycles and the sample's initial mass. The CL was measured at 100, 300, and 500 cycles or drum spins in the Los Angeles Machine (without steel spheres). The CL of each analyzed HMA (control, STOA, and LTOA) was calculated by averaging the results of the three samples. The test temperature was $20^{\circ} \mathrm{C}$.

\section{Results and Discussion}

\subsection{Marshall and ITS Tests}

The Marshall test results are shown in Table 1. When samples are subjected to aging processes of STOA and LTOA, the AV slightly increases, and VFA is reduced. In the reviewed literature, no mentions were found in that regard. However, this could have been because during the oven heating processes, part of the volatile, oleous, and lighter components of the asphalt binder are lost [40]. Even the asphalt binder's specific gravity increases because asphaltenes begin to prevail [53] and the molecular weight increases [42] Additionally, a small content of asphalt binder is lost in the LTOA process, when it adheres to the oven's grill that holds the samples. On the other hand, given that mixes retain more time at high temperature inside the oven, the probability that the asphalt binder penetrates and adheres more easily to the superficial pores of the aggregate increases.

Table 1. Marshall test results.

\begin{tabular}{|c|c|c|c|c|c|c|c|}
\hline Mixture & AC (\%) & $\mathrm{AV}(\%)$ & VMA (\%) & VFA (\%) & $\mathrm{S}(\mathbf{k N})$ & $\mathrm{F}(\mathrm{mm})$ & $\mathrm{S} / \mathrm{F}(\mathrm{kN} / \mathrm{mm})$ \\
\hline \multicolumn{8}{|c|}{ HMA-10 } \\
\hline Control & \multirow{3}{*}{5.8} & 4.51 & 17.52 & 76.32 & 10.14 & 3.86 & 2.63 \\
\hline STOA & & 4.87 & 18.22 & 73.29 & 11.19 & 3.78 & 2.96 \\
\hline LTOA & & 5.12 & 18.38 & 72.15 & 11.36 & 2.98 & 3.82 \\
\hline \multicolumn{8}{|c|}{ HMA-19 } \\
\hline Control & \multirow{3}{*}{5.3} & 3.66 & 15.83 & 76.89 & 12.44 & 3.70 & 3.36 \\
\hline STOA & & 4.56 & 16.99 & 73.16 & 12.91 & 3.52 & 3.67 \\
\hline LTOA & & 4.64 & 17.00 & 72.74 & 13.59 & 3.42 & 3.98 \\
\hline \multicolumn{8}{|c|}{ HMA-25 } \\
\hline Control & \multirow{3}{*}{4.5} & 6.33 & 16.93 & 62.64 & 11.19 & 3.78 & 2.96 \\
\hline STOA & & 6.68 & 17.21 & 61.23 & 11.62 & 3.37 & 3.45 \\
\hline LTOA & & 6.69 & 17.18 & 61.07 & 12.38 & 3.26 & 3.80 \\
\hline
\end{tabular}

In general terms, despite a slight increase in $\mathrm{AV}$ during the aging process, the stability of mixes increases and flow decreases, which generates an increase in S/F ratio. This is mainly given because of the increase in stiffness of asphalt binder when it ages. The mix with the greatest monotonic resistance in the Marshall test is HMA-19 (greatest S/F values). In comparison to the HMA-10 mix, HMA-25 presents greater S/F values in control mixes and in STOA. In the LTOA condition, both mixes present statistically similar 
values according to ANOVA analysis. For the case of the HMA-10 mix, it increases 1.127 and 1.453 times with relation to the control mix when it is subjected to STOA and LTOA procedures, respectively. These increases are of 1.093 and 1.182 times for the HMA-19 mix and of 1.164 and 1.284 times for the HMA-25 mix. According to ANOVA analysis, these S/F increases in mixes as a product of short-term or long-term aging are statistically significant. Compared with the STOA process, the S/F is 1.289, 1.082, and 1.103 times greater in HMA-10, HMA-19, and HMA-25 mixes, respectively, when samples are subjected to the LTOA procedure. The mix that underwent less changes in S/F ratio due to aging was HMA-19. The mix that registered the greatest changes in STOA procedure was HMA-25, while in LTOA, it was HMA-10.

The ITS test results are shown on Table 2. As in the Marshall test, the HMA-19 mix presents greater ITS values and HMA-10 presents the lowest. Additionally, ITSU and ITSC parameters increase when the mix ages. This is perhaps since in general, increases in stiffness in mixes generate increases in said parameters [54]. ITSU increases in mixes as a product of STOA aging were statistically significant. For the case of ITSC, said increases were not statistically significant. Increases or changes in ITSU between control samples and samples conditioned in STOA and LTOA are depicted on Figure 3. The mixes that are most susceptible to changes in their ITSU when they age are HMA-19 and HMA-25.

Table 2. ITS test results.

\begin{tabular}{|c|c|c|c|c|c|}
\hline Mixture & AC (\%) & $\mathrm{AV}(\%)$ & ITSU (kPa) & ITSC (kPa) & TSR (\%) \\
\hline \multicolumn{6}{|c|}{ HMA-10 } \\
\hline Control & & 4.22 & 1010.7 & 897.8 & 88.8 \\
\hline STOA & 5.8 & 4.77 & 1075.5 & 921.4 & 85.7 \\
\hline LTOA & & 4.95 & 1153.8 & 957.2 & 83.0 \\
\hline \multicolumn{6}{|c|}{ HMA-19 } \\
\hline Control & & 3.82 & 1125.2 & 1073.1 & 95.4 \\
\hline STOA & 5.3 & 4.46 & 1201.7 & 1078.4 & 89.7 \\
\hline LTOA & & 4.65 & 1296.6 & 1101.0 & 84.9 \\
\hline \multicolumn{6}{|c|}{ HMA-25 } \\
\hline Control & & 6.02 & 1099.6 & 982.3 & 89.3 \\
\hline STOA & 4.5 & 6.29 & 1122.1 & 989.0 & 88.1 \\
\hline LTOA & & 6.45 & 1224.9 & 1029.0 & 84.0 \\
\hline
\end{tabular}

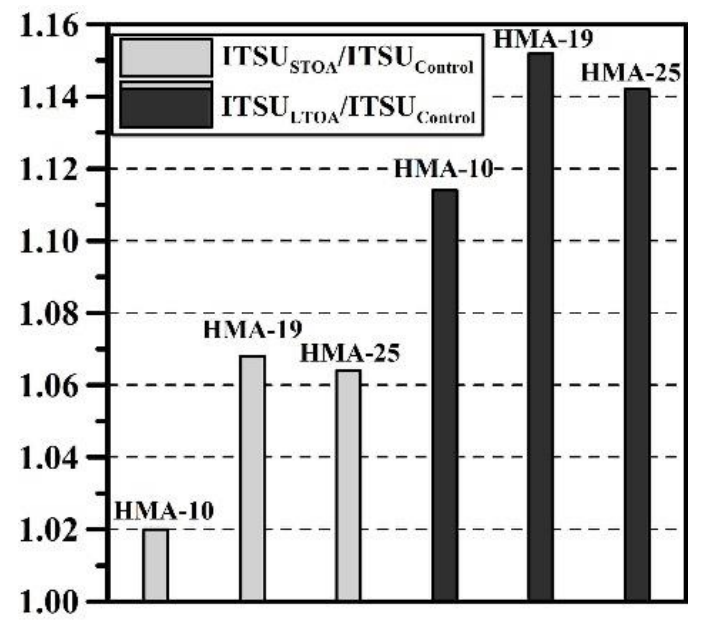

Figure 3. Relationship of ITSU values of control mixes and mixes conditioned in STOA and LTOA.

With regard to moisture damage resistance, the reviewed reference literature is ambiguous when it reports the effect of gradation on mixes. While some studies report that 
fine gradations tend to be more resistant to moisture damage mainly due to the smaller content of AV these mixes have [55,56], others conclude the contrary, arguing that it increases the specific surface of the aggregate, which could form a thinner asphalt film thickness, weakening the adhesion between the asphalt and aggregate [57]. Additionally, moisture damage resistance is a function of water transport mode within the mix, which is controlled by the air void sizes and their connectivity, diffusivity of water molecules in the mixture and asphalt binder, filler content, aggregate gradation, absorption, and geometry, among others [58-60]. In this study, the mix that displayed less moisture damage resistance was HMA-10, and the one that displayed the greatest moisture damage resistance was HMA-19. In addition, the TSR parameter is reduced when the mix ages, indicating a reduction in moisture damage resistance. When asphalt ages, it reduces its capacity to adhere to aggregates and to make the mix cohesive [8,61], which is mainly due to the loss of oleous asphalt binder components that contribute to its manageability. Added to this, aged asphalt binders contained a greater quantity of molecules and polar functional groups $[8,42,62,63]$, which causes asphaltenes to start to prevail (increasing stiffness and viscosity) over other components that contribute with adherence such as resins [64]. According to [65], adhesion is directly correlated with the non-polar fractions of asphalt binder while stiffness is likewise with polar fractions.

\subsection{Resilient Modulus and Permanent Deformation}

The RMs of HMA-10, HMA-19, and HMA-25 mixes (control, STOA, and LTOA) are shown in Figure 4. It is observable that the mix with lower stiffness (under any temperature, load frequency, and aging condition) is HMA-10, which is mainly due to its smaller particle size, finer gradation, and greater asphalt binder content. When comparing HMA-19 and HMA-25 mixes, there is no clear trend. At $30{ }^{\circ} \mathrm{C}$, the HMA-25 mix presents a slightly superior RM with relation to HMA-19, but said variation is not statistically significant (based on an ANOVA analysis). At 10 and $20^{\circ} \mathrm{C}$, the trend is the same when comparing the control mix with STOA (HMA-25 presents RMs that are slightly higher but not statistically significant). However, under the LTOA condition, the HMA-19 mix tends to be stiffer, although variations continue to not be statistically significant when compared with the HMA-25. The lack of a clearly defined trend between both mixes is rooted in the fact that $\mathrm{RM}$ is a parameter that depends on multiple variables. For example, mixes that have a greater particle size tend to have a greater contribution in RM (in this case, HMA-25), while mixes with a lower AV tend to present a greater RM (this is the case of HMA-19).

A parameter used to evaluate the susceptibility of mixes for aging is the relationship between stiffness of the aged and unaged mix [66,67]. As a result of such reasons, the RM values of STOA and LTOA aged samples with relationship to the control mix were calculated $\left(\mathrm{RM}_{\mathrm{STOA}} / \mathrm{RM}_{\mathrm{Control}}, \mathrm{RM}_{\mathrm{LTOA}} / \mathrm{RM}_{\mathrm{Control}}\right)$. The relationship $\mathrm{RM}_{\mathrm{LTOA}} / \mathrm{RM}_{\mathrm{STOA}}$ was also calculated. These relationships or increases in RM as a product of asphalt binder aging are depicted in Figures 5 and 6. Likewise, the averages (with relationship to values reported for each load frequency) of ratios $\mathrm{RM}_{\mathrm{STOA}} / \mathrm{RM}_{\mathrm{Control}}, \mathrm{RM}_{\mathrm{LTOA}} / \mathrm{RM}_{\mathrm{Control}}$, and $\mathrm{RM}_{\mathrm{LTOA}} / \mathrm{RM}_{\mathrm{STOA}}$ are depicted in Table 3. It is observable that these relationships are greater when the test temperature increases and load frequency decreases, which is mainly given because of the asphalt binders' visco-elastic response. With regard to the effect of gradation, there is no existing clear trend. The HMA-10 mix tends to undergo greater $\mathrm{RM}_{\mathrm{STOA}} / \mathrm{RM}_{\mathrm{Control}}$ and $\mathrm{RM}_{\mathrm{LTOA}} / \mathrm{RM}_{\mathrm{Control}}$ ratios (greater increases in stiffness or susceptibility for aging) when the test temperature is $10^{\circ} \mathrm{C}$. Under this temperature, the mix that undergoes the smallest increases is HMA-25. At $20{ }^{\circ} \mathrm{C}$, the mix that is more susceptible to changing its RM in STOA condition is still HMA-10; however, in the long term, the most susceptible one is HMA-19. Under this temperature, HMA-25 maintains itself with the least changes in RM. At $30^{\circ} \mathrm{C}$, a greater susceptibility can be observed in the HMA-19 mix when it ages in the short term and in the HMA-25 mix when it ages in the long term. Additionally, the greatest changes in RM between STOA and LTOA condition 
are presented in the HMA-19 mix when the test temperature is 10 and $20^{\circ} \mathrm{C}$, while for the case of $30^{\circ} \mathrm{C}$, these take place in HMA-25.

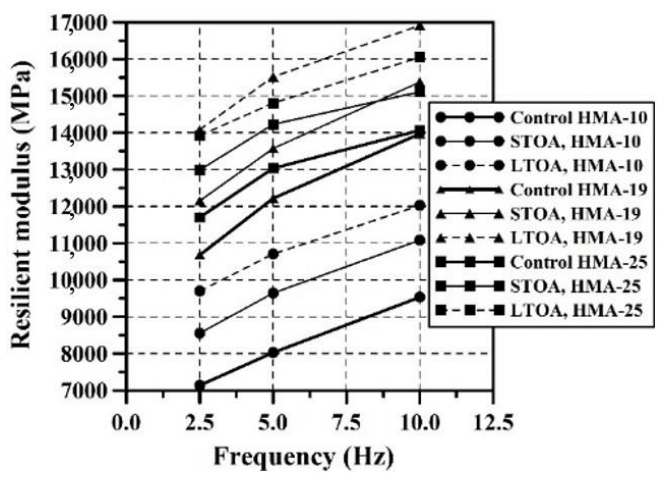

(a)

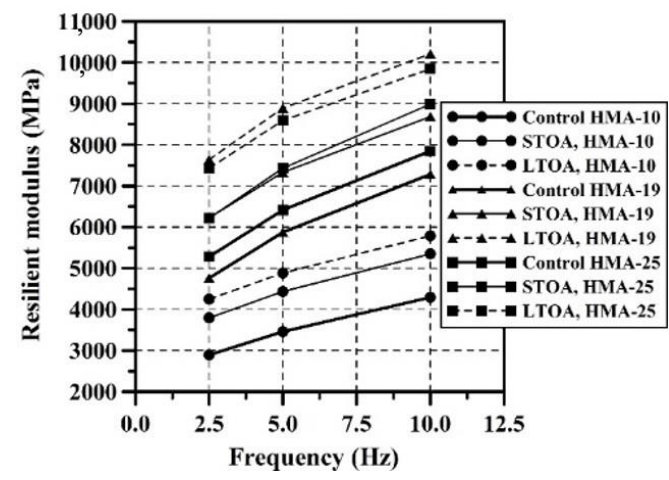

(b)

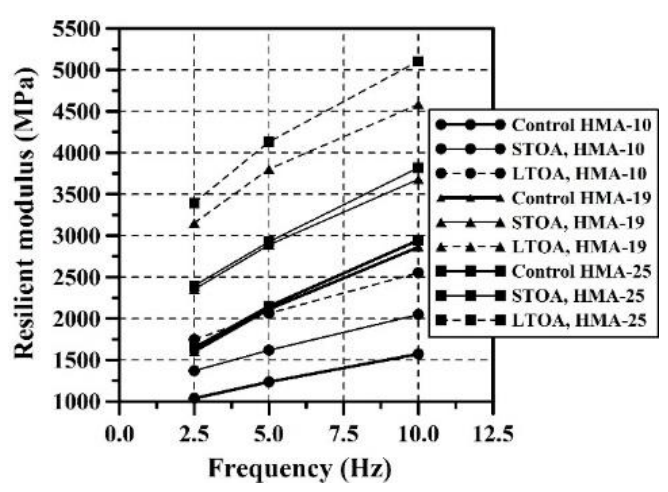

(c)

Figure 4. Resilient modulus at (a) $10^{\circ} \mathrm{C}$, (b) $20^{\circ} \mathrm{C}$, and (c) $30^{\circ} \mathrm{C}$.

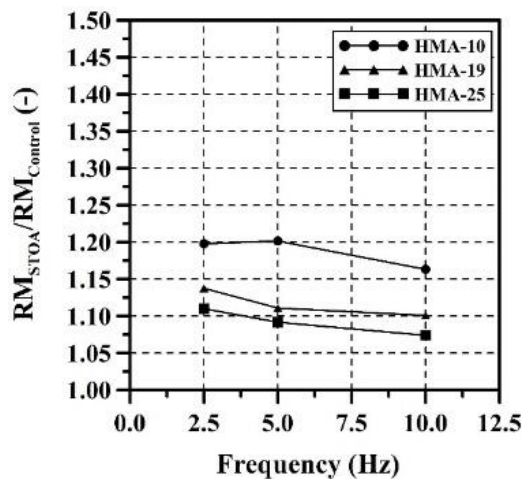

(a)

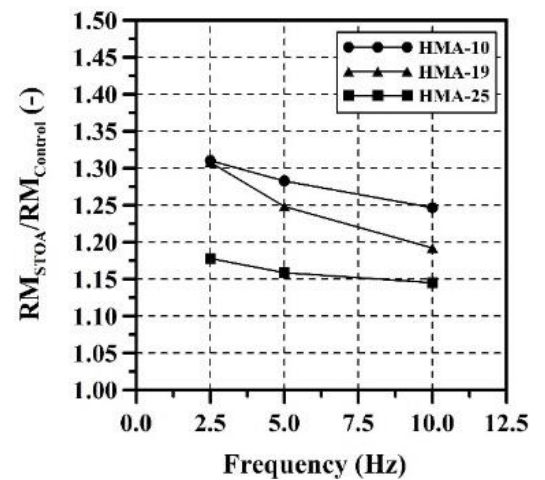

(b)

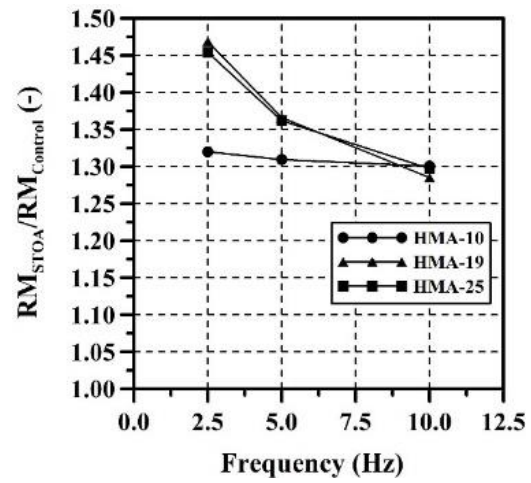

(c)

Figure 5. $\mathrm{RM}_{\mathrm{STOA}} / \mathrm{RM}_{\mathrm{Control}}$ ratio at (a) $10^{\circ} \mathrm{C}$, (b) $20^{\circ} \mathrm{C}$, and (c) $30^{\circ} \mathrm{C}$. 


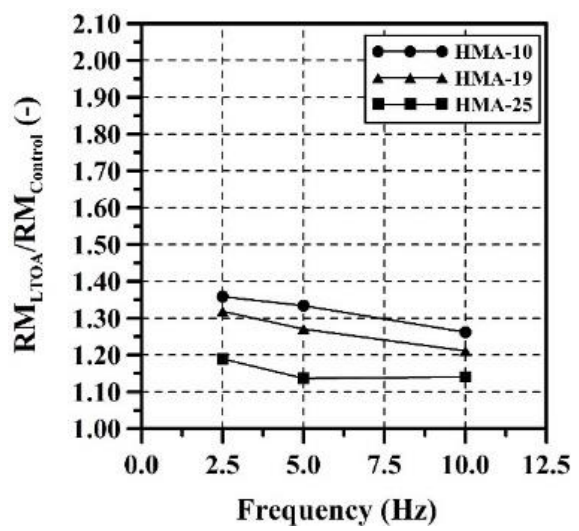

(a)

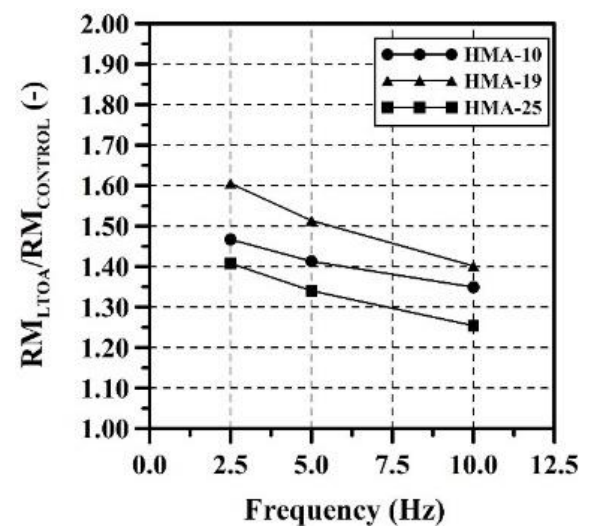

(b)

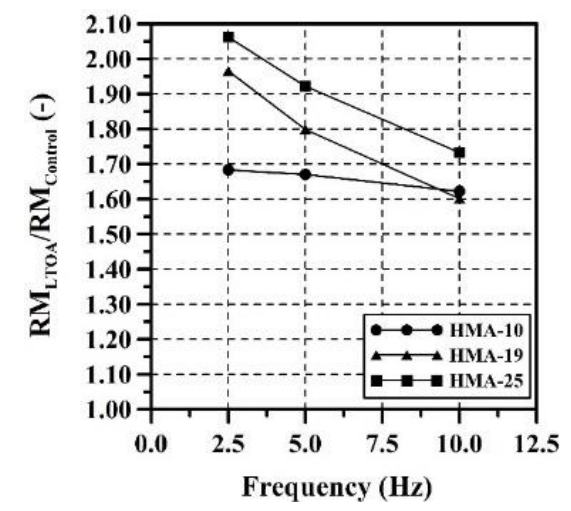

(c)

Figure 6. $\mathrm{RM}_{\mathrm{LTOA}} / \mathrm{RM}_{\mathrm{Control}}$ ratio at (a) $10^{\circ} \mathrm{C}$, (b) $20^{\circ} \mathrm{C}$, and (c) $30^{\circ} \mathrm{C}$.

Table 3. RM aging susceptibility ratios.

\begin{tabular}{|c|c|c|c|c|c|c|c|c|}
\hline \multicolumn{3}{|c|}{$\mathrm{RM}_{\mathrm{STOA}} / \mathbf{R M}_{\text {Control }}$} & \multicolumn{3}{|c|}{$\mathrm{RM}_{\mathrm{LTOA}} / \mathbf{R M}_{\text {Control }}$} & \multicolumn{3}{|c|}{$\mathbf{R M}_{\text {LTOA }} / \mathbf{R M}_{\mathrm{STOA}}$} \\
\hline $10^{\circ} \mathrm{C}$ & $20^{\circ} \mathrm{C}$ & $30^{\circ} \mathrm{C}$ & $10^{\circ} \mathrm{C}$ & $20^{\circ} \mathrm{C}$ & $30^{\circ} \mathrm{C}$ & $10^{\circ} \mathrm{C}$ & $20^{\circ} \mathrm{C}$ & $30^{\circ} \mathrm{C}$ \\
\hline \multicolumn{9}{|c|}{ HMA-10 } \\
\hline $1.188 \pm 0.021$ & $1.280 \pm 0.032$ & $1.310 \pm 0.010$ & $1.318 \pm 0.050$ & $1.410 \pm 0.059$ & $1.658 \pm 0.032$ & $1.110 \pm 0.024$ & $1.101 \pm 0.019$ & $1.266 \pm 0.016$ \\
\hline \multicolumn{9}{|c|}{ HMA-19 } \\
\hline $1.117 \pm 0.019$ & $1.249 \pm 0.058$ & $1.373 \pm 0.092$ & $1.267 \pm 0.054$ & $1.507 \pm 0.102$ & $1.788 \pm 0.183$ & $1.134 \pm 0.031$ & $1.205 \pm 0.027$ & $1.300 \pm 0.048$ \\
\hline \multicolumn{9}{|c|}{ HMA-25 } \\
\hline $1.092 \pm 0.018$ & $1.161 \pm 0.016$ & $1.371 \pm 0.079$ & $1.156 \pm 0.030$ & $1.334 \pm 0.077$ & $1.906 \pm 0.165$ & $1.058 \pm 0.016$ & $1.149 \pm 0.050$ & $1.388 \pm 0.045$ \\
\hline
\end{tabular}

The permanent deformation resistance of a mix depends on a combination of factors such as asphalt binder type and stiffness, gradation, type form and texture of the aggregate, $\mathrm{AV}$, and VFA, among others [68]. The results of the permanent deformation tests that are presented in Figure 7 are coherent with those obtained in the Marshall test and RM test. It is possible to observe an increase in permanent deformation resistance when mixes age as a product of the increase in stiffness in asphalt binder, increase in S/F ratio, and increase in RM. This increase in resistance can help to aid in resisting the rutting phenomenon in high-temperature climates [39]. The mix with the least rutting resistance is HMA-10, which is mainly due to its lower RM value. The most resistant mixes are those that present a greater particle size and RM (HMA-19 and HMA-25). With regard to the influence of aging, HMA-25 was the mix that was least susceptible to changing its permanent deformation resistance (displacement of the control mix at 3600 load cycles $-\Delta_{3600}$ was of 1.03 and 1.09 times with relation to the STOA and LTOA condition, respectively). In the case of the 
other two mixes, the susceptibility was similar. In control HMA-10, $\Delta_{3600}$ was 2.19 times greater with relation to the STOA and LTOA condition, respectively, while in control HMA-19, it was 1.17 and 1.90 times greater.

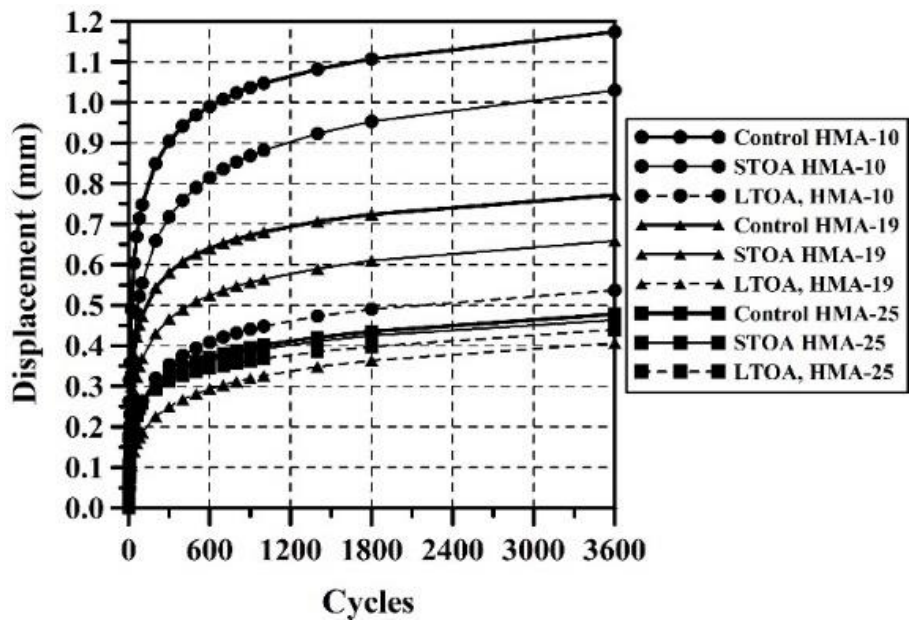

Figure 7. Displacement vs. number of load cycles.

\subsection{Fatigue Resistance}

The results of fatigue tests are displayed in Figure 8 . The amplitude of stress in $\mathrm{kPa}$ necessary for samples to fail at $10^{6}$ load cycles $\left(\sigma_{6}\right)$ is shown in Figure 9 . For the case of control mixes, the mix with greater fatigue resistance was HMA-19, while the mix that displayed the least resistance was HMA-25. Under controlled stress, in general, the stiffer asphalt mixtures are the ones that have the greatest fatigue resistance [69-72]. However, in this case, control HMA-10 with less stiffness undergoes greater fatigue resistance than control HMA-25, which is mainly since this last one displays a superior AV.

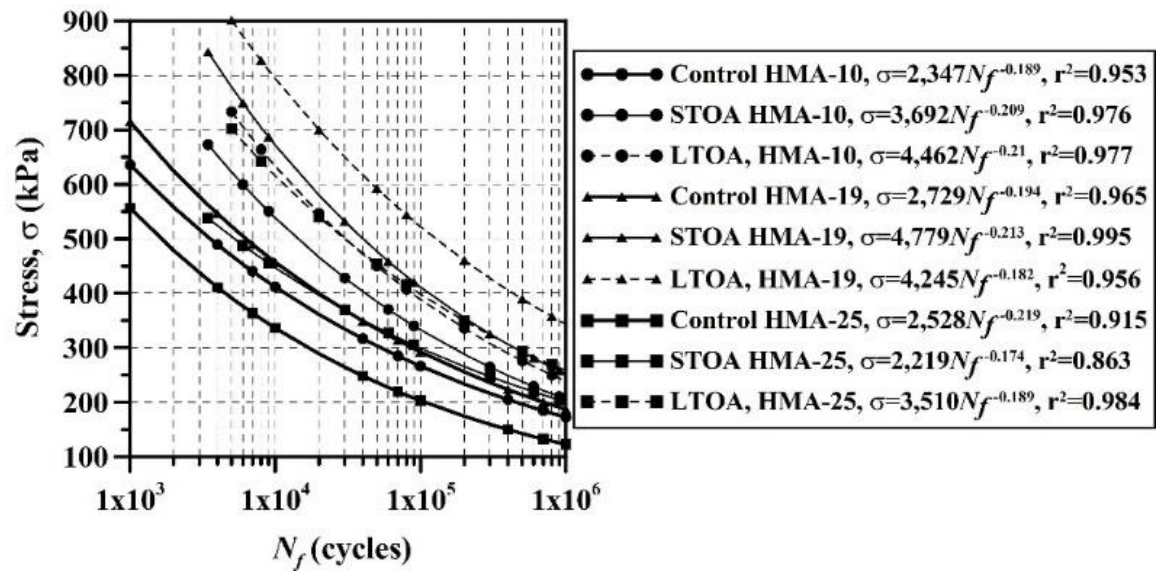

Figure 8. Fatigue test results.

On the other hand, fatigue resistance increased when mixes aged, which was mainly given because of what was mentioned above (under controlled stress, asphalt mixes undergo an increase in fatigue life when stiffness increases). Table 4 shows how the $N f$ of mixes increased on average when these aged. HMA-25 presented the greatest increases in fatigue life upon aging (greater $N_{f S T O A} / N_{f \text { Control }}$ and $N_{f \mathrm{LTOA}} / N_{f \text { Control }}$ ratios). However, HMA-19 displays less AV and greater ITS values than HMA-25, which contributes to positioning it as the mix with the greatest fatigue resistance. The mix that least underwent increases in $N_{f}$ was HMA-10. This led to that under LTOA condition, HMA-25 underwent a similar fatigue resistance (even with a greater $\sigma_{6}$ ) than HMA-10, even though it has greater AV. All these increases were statistically significant based on ANOVA analysis. 


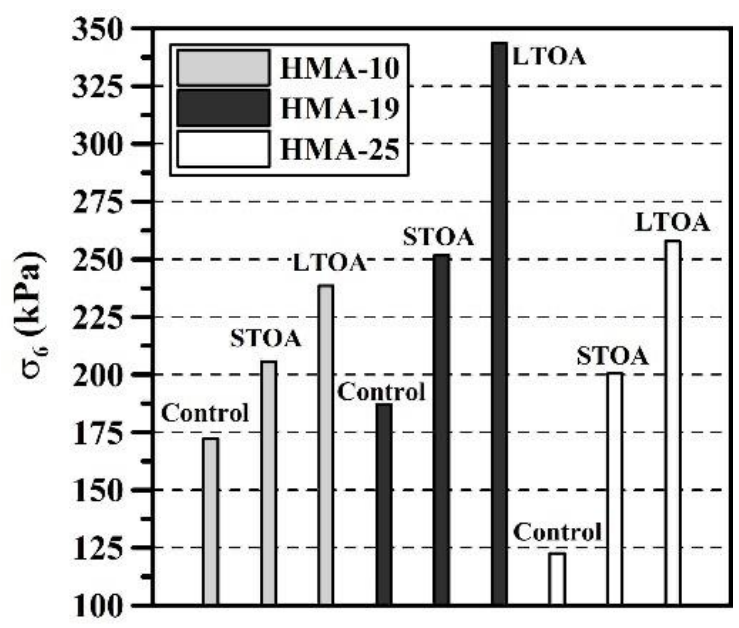

Figure 9. $\sigma_{6}$ of control mixes, STOA and LTOA.

Table 4. Ratio between $N_{f}$ of control mixes, STOA and LTOA.

\begin{tabular}{cccc}
\hline Mixture & $N_{f \text { STOA }} / N_{f \text { Control }}$ & $N_{f \text { LTOA }} / N_{f \text { Control }}$ & $N_{f \text { LTOA }} / N_{f \text { STOA }}$ \\
\hline HMA-10 & $1.257 \pm 0.045$ & $1.469 \pm 0.060$ & $1.168 \pm 0.006$ \\
HMA-19 & $1.415 \pm 0.048$ & $1.781 \pm 0.038$ & $1.261 \pm 0.070$ \\
HMA-25 & $1.461 \pm 0.117$ & $1.949 \pm 0.104$ & $1.337 \pm 0.036$ \\
\hline
\end{tabular}

\subsection{Cantabro Test}

The Cantabro test results are presented in Table 5. Similar results were reported by $[43,52]$. If the results of CL vs. cycles were to be graphed, one would obtain a linear trend, whose approximate slope (named Cantabro Index-CI in this study) may be obtained mathematically using Equation (1):

$$
\mathrm{CI}=\frac{C L_{C f}-C L_{C i}}{C f-C i}
$$

where $C L_{C f}$ is the $C L$ obtained in the final cycles $(C f)$, and $C L_{C i}$ is the $C L$ obtained in the initial cycles $(C i)$. In this study, $C f$ and $C i$ are 500 and 100 cycles, respectively.

Table 5. Cantabro test results.

\begin{tabular}{|c|c|c|c|c|c|c|}
\hline \multirow{2}{*}{ Mixture } & \multirow{2}{*}{$\mathrm{AC}(\%)$} & \multirow{2}{*}{$\operatorname{AV}(\%)$} & \multicolumn{3}{|c|}{ CL (\%) } & \multirow{2}{*}{$\begin{array}{l}\text { CI (\%/Cycles, } \\
\text { in Thousands) }\end{array}$} \\
\hline & & & 100 Cycles & 300 Cycles & 500 Cycles & \\
\hline \multicolumn{7}{|c|}{ HMA-10 } \\
\hline Control & & 4.31 & 2.06 & 3.15 & 4.45 & 5.975 \\
\hline STOA & 5.8 & 4.70 & 2.73 & 4.61 & 5.97 & 8.100 \\
\hline LTOA & & 5.02 & 3.36 & 5.12 & 6.91 & 8.875 \\
\hline \multicolumn{7}{|c|}{ HMA-19 } \\
\hline Control & & 4.12 & 2.20 & 3.27 & 4.87 & 6.675 \\
\hline STOA & 5.3 & 4.71 & 2.55 & 4.23 & 5.60 & 7.625 \\
\hline LTOA & & 4.95 & 3.29 & 4.77 & 6.52 & 8.075 \\
\hline \multicolumn{7}{|c|}{ HMA-25 } \\
\hline Control & & 6.10 & 3.10 & 4.42 & 5.89 & 6.975 \\
\hline STOA & 4.5 & 6.34 & 3.44 & 5.16 & 6.77 & 8.325 \\
\hline LTOA & & 6.52 & 3.86 & 5.55 & 7.48 & 9.050 \\
\hline
\end{tabular}


When the CL and CI parameters increase, it signifies a reduction of abrasion wear resistance. It is observable that both parameters increase when the mix ages. This can take place given that when asphalt binder ages, it reduces its capacity to adhere to the aggregate and to make the mix cohesive [73]. Additionally, when asphalt binder ages, the proportion of maltenes/asphaltenes is reduced, resulting in a material that is stiffer and brittle $[74,75]$, which makes it more susceptible to fissures or cracking under any type of abrasive load [76,77].

The control mixes that underwent greater and smaller abrasion wear resistance were HMA-10 and HMA-25, respectively. However, when mixes age, this behavior changes and HMA-19 undergoes greater resistance. Upon aging, HMA-25 continues being the mix with least resistance. This is mainly because the HMA-25 mix has greater AV and lower VFA. Figure 10 shows how $C L$ increased in mixes when they aged. It is observable that the mix that underwent the least CL changes was HMA-25, while the greatest changes occurred in HMA-10. This was perhaps due to the greater content of asphalt binder that aged in HMA-10, which became brittle and was more easily detached under abrasive load.

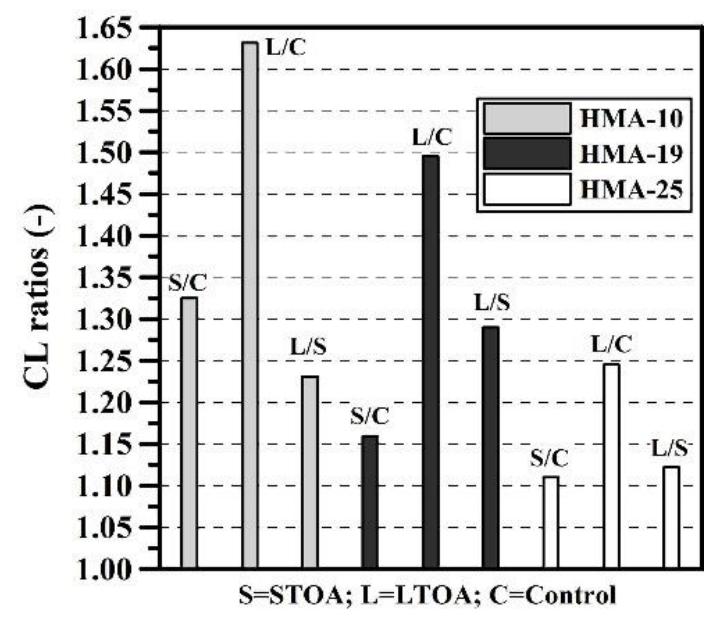

Figure 10. CL ratio of control mixes, STOA, and LTOA. Summary of results.

Normally, mixes that present greater $\mathrm{AV}$, greater particle sizes, coarse gradations, and lower VFA are more susceptible to aging $[8,40,74,78-80]$. Generally, this conclusion is based on the way it changes in stiffness (mainly in RM tests) of aged mixes with relation to the control mix. However, this study evaluated the change in other properties. Mixes that underwent the least and greatest changes under STOA and LTOA conditions with relation to the control mix are shown in Table 6 . When two mixes appear in a box, it means that they underwent similar changes-in other words, changes that are not statistically significant based on ANOVA analysis.

Table 6. Summary of aging susceptibility ratios of HMA mixes.

\begin{tabular}{ccccc}
\hline \multirow{2}{*}{ Parameter } & \multicolumn{2}{c}{ STOA } & \multicolumn{2}{c}{ LTOA } \\
\cline { 2 - 5 } & Greater & Less & Greater & Less \\
\cline { 2 - 5 } S/F & HMA-25 & HMA-19 & HMA-10 & HMA-19 \\
ITSU & HMA-19 & HMA-10 & HAM-19 & HMA-10 \\
RM $\left(10^{\circ} \mathrm{C}\right)$ & HMA-10 & HMA-25 & HMA-10 & HMA-25 \\
$\mathrm{RM}\left(20^{\circ} \mathrm{C}\right)$ & HMA-10 & HMA-25 & HMA-19 & HMA-25 \\
$\mathrm{RM}\left(30^{\circ} \mathrm{C}\right)$ & HMA-19 and HMA-25 & HMA-10 & HMA-25 & HMA-10 \\
$\Delta_{3600}$ & HMA-10 HMA-19 & HMA-25 & HMA-10 & HMA-25 \\
$N_{f}$ (fatigue $)$ & HMA-25 & HMA-10 & HMA-25 & HMA-10 \\
CL & HMA-10 & HMA-25 & HMA-10 & HMA-25 \\
\hline
\end{tabular}


Generally, the susceptibility of mixes for aging is obtained by measuring increases in its stiffness, in other words, by comparing it or relating the stiffness in an aged state with relation to a control sample (unaged). The increase in RM is especially one that is widely used. Since asphalt is a material that has a viscous behavior, mixes undergo changes in their properties when they are subjected to different temperatures and load frequencies. This study observed that the increases in RM of mixes that occurred due to aging were greater when the test temperature increased and load frequency decreased. In terms of the effect of gradation upon increases in RM, there was no clear trend. It was expected that the greatest changes would be observed in mix HMA-25, which has a greater AV content. However, at $10{ }^{\circ} \mathrm{C}$, the mix HMA-10 tends to display the greatest increases in RM (under STOA and LTOA conditions), while HMA-25 displays the smallest. At $20^{\circ} \mathrm{C}$, the mix that is most susceptible to changing its RM in STOA condition is HMA-10, while in LTOA, it is HMA-19. Under this temperature, HMA-25 undergoes the smallest changes in RM. At $30{ }^{\circ} \mathrm{C}$ in STOA condition, the HMA-19 mix undergoes the greatest increases, while in LTOA, it is HMA-25.

Below, there is a summary of the most important aspects of each test:

- In the Marshall test, the mix that underwent greater changes in resistance under monotonic load (greater S/F ratio) was HMA-19. In turn, this mix obtained the smallest increases in S/F ratio in STOA and LTOA conditions (in theory, this property is less susceptibility to change upon aging). The mix that underwent the lowest resistance under monotonic load in this test was HMA-10, and in LTOA condition, it presented the greatest increases. In STOA condition, the greatest increases occurred in HMA-25.

- In the ITS test, the mix that underwent the greatest changes in resistances (ITSU and ITSC) was HMA-19. In turn, this mix obtained the greatest increases in ITS-U under STOA and LTOA conditions (in theory, this property has greater susceptibility to change upon aging). Despite that, this is in theory the mix that is most susceptible to changing its resistance due to the effects of aging in this test; it was the one that underwent the greatest moisture damage resistance. The mix that underwent less resistance under monotonic load in this test and the least increases in ITSU was HMA-10. Although it is the one that is least susceptible to aging, it was the one that underwent the least moisture damage resistance.

- The mixes that were most resistant to the phenomenon of permanent deformation were HMA-19 and HMA-25. The mix that was least susceptible to change resistance to permanent deformation under STOA and LTOA conditions was HMA-25. Under the STOA condition, HMA-10 and HMA-19 mixes underwent the greatest changes, while HMA-10 did likewise in the LTOA condition.

- In general terms, the mix with greater resistance to fatigue under controlled stress was HMA-19, while the one with less resistance was HMA-25. The mixes that underwent greater and smaller increases in fatigue life upon aging were HMA-25 and HMA-10, respectively.

- In the initial state (unaged), the mixes that underwent the greatest and lowest resistance to abrasion wear in the Cantabro Test were HMA-10 and HMA-25, respectively. When mixes age, HMA-19 underwent the greatest resistance, while the one that underwent the least resistance was HMA-25. The greatest and smallest changes in the test (increase in CL) were underwent by HMA-10 and HMA-25 mixes, respectively.

\section{Conclusions}

This study measured the mechanical properties of three HMA mixes (with different gradations) when they age in the short term (STOA) and long term (LTOA). Based on the results obtained, the conclusions are the following:

- When asphalt binder ages, it becomes stiff. This increase in stiffness generated significant increases in resistance under monotonic load (increases in S/F ratio in the Marshall test and increase in parameters ITSU and ITSC in the ITS test) and cyclic 
load (increases of RM, decreases in $\Delta_{3600}$ in the permanent deformation test, and increases of $\sigma_{6}$ in the test of fatigue under controlled stress). The above could be seen as an indicator of good performance in mixes for resisting vehicle loads in hightemperature climates and in asphalt pavements with thicker asphalt layers. However, in low-temperature climates and asphalt pavements with thin asphalt layers, the opposite could occur. Additionally, this increase in stiffness contributes to reducing the moisture damage resistance (reduction of TSR in the ITS test) and to abrasion (increase in CL and CI in the Cantabro test).

- It is observable that HMA-19 undergoes the changes that give it the best performances in most of the evaluated properties.

- Regarding evaluating the effects of gradation upon the susceptibility of mixes to age, there is no existing clearly defined trend. This susceptibility changes depending on the test performed and the property measured.

- The traditional way of obtaining the susceptibility of mixtures to aging, based only on the relationships of stiffness values in aged and unaged states, must be reviewed, since using this relationship, the influence of gradation on aging susceptibility changes depending on the test temperature.

- The lack of a clear trend in the effects of gradation upon aging of HMAs motivates the development of future studies to continue deepening this discussion.

Author Contributions: Conceptualization, H.A.R.-Q., C.A.Z.-M. and S.B.C.-P.; methodology, H.A.R.Q. and C.A.Z.-M.; validation and formal analysis, S.B.C.-P.; H.A.R.-Q. and C.A.Z.-M.; resources, S.B.C.-P., H.A.R.-Q. and C.A.Z.-M.; writing—original draft preparation, H.A.R.-Q. and C.A.Z.-M.; writing - review and editing, S.B.C.-P. and H.A.R.-Q.; funding acquisition, S.B.C.-P. All authors have read and agreed to the published version of the manuscript.

Funding: This research received no external funding.

Institutional Review Board Statement: Not applicable.

Informed Consent Statement: Not applicable.

Data Availability Statement: Not applicable.

Acknowledgments: In the case of the author Saieth Baudilio Chaves-Pabón it is mentioned that it is a product of his academic work as a professor at the Universidad Militar Nueva Granada. We thank the participating institutions (Universidad Militar Nueva Granada and Universidad Distrital Francisco José de Caldas) for the support granted to researchers.

Conflicts of Interest: The authors declare no conflict of interest.

\section{Abbreviations}

AC Asphalt cement

AV Air void content

CI Cantabro index

CL Cantabro loss

CT Compaction temperature

F Flow

HMA Hot-mix asphalt

ITS Indirect tensile strength

ITSC Indirect tensile strength, conditioned

ITSU Indirect tensile strength, unconditioned

LMS Large molecular size

LTOA Long-term oven aging

LVDT Linear variable differential transformer

MT Mix temperature

NAT Nottingham asphalt tester

$\mathrm{Nf}$ Number of load cycles to failure 


$\begin{array}{ll}\text { OAC } & \text { Optimal asphalt content } \\ \text { PAV } & \text { Pressure aging vessel } \\ \text { RM } & \text { Resilient modulus } \\ \text { RTFOT } & \text { Rolling thin film oven test } \\ \text { S } & \text { Stability } \\ \text { STOA } & \text { Short-term oven aging } \\ \text { TDC } & \text { Top-down type cracking } \\ \text { TSR } & \text { Tensile strength ratio } \\ \text { VFA } & \text { Voids filled with asphalt } \\ \text { VMA } & \text { Voids in the mineral aggregate }\end{array}$

\section{References}

1. Airey, G.D. State of the Art Report on Ageing Test Methods for Bituminous Pavement Materials. Int. J. Pavement Eng. 2003, 4, 165-176. [CrossRef]

2. Zadshir, M.; Hosseinnezhad, S.; Ortega, R.; Chen, F.; Hochstein, D.; Xie, J.; Yin, H.; Parast, M.M.; Fini, E.H. Application of a Biomodifier as Fog Sealants to Delay Ultraviolet Aging of Bituminous Materials. J. Mater. Civ. Eng. 2018, 30, 04018310. [CrossRef]

3. Zhang, H.; Chen, Z.; Xu, G.; Shi, C. Evaluation of aging behaviors of asphalt binders through different rheological indices. Fuel 2018, 221, 78-88. [CrossRef]

4. Chaves-Pabón, S.B.; Rondón-Quintana, H.A.; Bastidas-Martínez, J.G. Aging of asphalt binders and asphalt mixtures. Summary part I: Effect on physical-chemical properties. Int. J. Civ. Eng. Technol. 2019, 10, 259-273.

5. Abu Qtaish, L.; Nazzal, M.D.; Abbas, A.; Kaya, S.; Akinbowale, S.; Arefin, M.S.; Kim, S.-S. Micromechanical and Chemical Characterization of Foamed Warm-Mix Asphalt Aging. J. Mater. Civ. Eng. 2018, 30, 04018213. [CrossRef]

6. Mikhailenko, P.; Kou, C.; Baaj, H.; Poulikakos, L.; Cannone-Falchetto, A.; Besamusca, J.; Hofko, B. Comparison of ESEM and physical properties of virgin and laboratory aged asphalt binders. Fuel 2018, 235, 627-638. [CrossRef]

7. Chaves-Pabón, S.B.; Rondón-Quintana, H.A.; Bastidas-Martínez, J.G. Aging of asphalt binders and asphalt mixtures. Summary part II: Aging simulation and aging reduction techniques. Int. J. Civ. Eng. Technol. 2019, 10, 274-287.

8. Tauste, R.; Moreno-Navarro, F.; Sol-Sánchez, M.; Rubio-Gámez, M. Understanding the bitumen ageing phenomenon: A review. Constr. Build. Mater. 2018, 192, 593-609. [CrossRef]

9. Wang, F.; Xiao, Y.; Cui, P.; Lin, J.; Li, M.; Chen, Z. Correlation of asphalt performance indicators and aging Degrees: A review. Constr. Build. Mater. 2020, 250, 118824. [CrossRef]

10. Chen, X.; Ning, Y.; Gu, Y.; Zhao, R.; Tong, J.; Wang, J.; Zhang, X.; Wen, W. Evaluating the Rheological, Chemical and Morphological Properties of SBS Modified Asphalt-Binder under Multiple Aging and Rejuvenation Cycles. Appl. Sci. 2021, 11, 9242. [CrossRef]

11. Wu, B.; Luo, C.; Pei, Z.; Chen, C.; Xia, J.; Xiao, P. Evaluation of the Aging of Styrene-Butadiene-Styrene Modified Asphalt Binder with Different Polymer Additives. Materials 2021, 14, 5715. [CrossRef] [PubMed]

12. Wang, T.; Wei, X.; Zhang, D.; Shi, H.; Cheng, Z. Evaluation for Low Temperature Performance of SBS Modified Asphalt by Dynamic Shear Rheometer Method. Buildings 2021, 11, 408. [CrossRef]

13. Suo, Z.; Nie, L.; Xiang, F.; Bao, X. The Effect of Waste Plant Oil on the Composition and Micro-Morphological Properties of Old Asphalt Composition. Buildings 2021, 11, 407. [CrossRef]

14. Abu El-Maaty Behiry, A.E. Optimization of hot mix asphalt performance based on aggregate selection. Int. J. Pavement Eng. 2016, 17, 924-940. [CrossRef]

15. Zhang, Y.; Luo, X.; Onifade, I.; Huang, X.; Lytton, R.L.; Birgisson, B. Mechanical evaluation of aggregate gradation to characterize load carrying capacity and rutting resistance of asphalt mixtures. Constr. Build. Mater. 2019, 205, 499-510. [CrossRef]

16. Radhakrishnan, V.; Sri, M.R.; Reddy, K.S. Sensitivity of rutting and moisture resistance of asphalt mixes to gradation and design air void content. Int. J. Pavement Eng. 2018, 21, 1035-1043. [CrossRef]

17. Finn, F.N. Factors Involved in the Design of Asphaltic Pavement Surfaces; NCHRP Report 39, Transportation Research Board; Materials Research \& Development, Inc.: Washington, DC, USA, 1967.

18. Sholz, T.V. Durability of Bituminuos Paving Mixtures. Ph.D. Thesis, University of Notthingham, Notthingham, UK, 2015.

19. AASHTO. Standard Practice for Mixture Conditioning of Hot Mix Asphalt (HMA); AASHTO R30; AASHTO: Washington, DC, USA, 2002.

20. Von Quintus, H.L.; Scherocman, J.A.; Hughes, C.S.; Kennedy, T.W. Asphalt-Aggregate Mixture Analysis System; NCHRP Report 338, Transportation Research Board; National Research Council: Washington, DC, USA, 1991.

21. Bell, C.; Wieder, A.; Fellin, M. Laboratory Aging of Asphalt-Aggregate Mixtures: Field Validation; Strategic Highway Research Program Report No. SHRP-A-390; National Research Council: Washington, DC, USA, 1994.

22. AASHTO. Standard Method of Test for Specific Gravity and Absorption of Coarse Aggregate; AASHTO T 85; AASHTO: Washington, DC, USA, 1991.

23. AASHTO. Standard Method of Test for Specific Gravity and Absorption of Fine Aggregate; AASHTO T 84; AASHTO: Washington, DC, USA, 2000.

24. AASHTO. Standard Method of Test for Resistance to Degradation of Small-Size Coarse Aggregate by Abrasion and Impact in the Los Angeles Machine; AASHTO T 96; AASHTO: Washington, DC, USA, 2002. 
25. AASHTO. Standard Method of Test for Resistance of Coarse Aggregate to Degradation by Abrasion in the Micro-Deval Apparatus; AASHTO T 327; AASHTO: Washington, DC, USA, 2005.

26. DNER. Avaliação da resistência mecânica pelo método dos 10\% de finos [Evaluation of Mechanical Resistance to Coarse Aggregate Using 10\% Method]; DNER-ME 096; Departamento Nacional de Infraestrutura de Transporte: Rio de Janeiro, Brazil, 1998.

27. ASTM. Standard Test Method for Determining the Percentage of Fractured Particles in Coarse Aggregate; ASTM D5821; ASTM: West Conshohocken, PA, USA, 2001.

28. AASHTO. Standard Method of Test for Soundness of Aggregate by Use of Sodium Sulfate or Magnesium Sulfate; AASHTO T 104; AASHTO: Washington, DC, USA, 1999.

29. ASTM. Standard Test Methods for Liquid Limit, Plastic Limit, and Plasticity Index of Soils; ASTM D4318; ASTM: West Conshohocken, PA, USA, 2000.

30. ASTM. Standard Test Method for Flat Particles, Elongated Particles, or Flat and Elongated Particles in Coarse Aggregate; ASTM D4791; ASTM: West Conshohocken, PA, USA, 2019.

31. ASTM. Standard Test Method for Penetration of Bituminous Materials; ASTM D5/D5M; ASTM: West Conshohocken, PA, USA, 2013.

32. ASTM. Standard Test Method for Softening Point of Bitumen (Ring-and-Ball Apparatus); ASTM D36; ASTM: West Conshohocken, PA, USA, 2006.

33. NLT. Método para Determinar la Variación de la Consistencia del betún Asfáltico con los Cambios de Temperatura (Susceptibilidad) [Method to Determine the Variation in the Consistency of Asphalt Bitumen with Temperature Changes (Susceptibility)]; NLT 181; Normas NLT: Madrid, Spain, 1988.

34. AASHTO. Standard Method of Test for Specific Gravity of Semi-Solid Asphalt Materials; AASHTO T 228; AASHTO: Washington, DC, USA, 2004.

35. ASTM. Standard Test Method for Ductility of Bituminous Materials; ASTM D113; ASTM: West Conshohocken, PA, USA, 1999.

36. ASTM. Standard Test Method for Effect of Heat and Air on a Moving Film of Asphalt (Rolling Thin-Film Oven Test); ASTM D2872-12e1; ASTM: West Conshohocken, PA, USA, 2012.

37. ASTM. Standard Practice for Accelerated Aging of Asphalt Binder Using a Pressurized Aging Vessel (PAV); ASTM D6521; ASTM: West Conshohocken, PA, USA, 2019.

38. ASTM. Standard Test Method for Viscosity Determination of Asphalt at Elevated Temperatures Using a Rotational Viscometer; ASTM D4402/D4402M; ASTM: West Conshohocken, PA, USA, 2015.

39. Gómez-Meijide, B.; Ajam, H.; González, P.L.; Garcia, A. Effect of ageing and RAP content on the induction healing properties of asphalt mixtures. Constr. Build. Mater. 2018, 179, 468-476. [CrossRef]

40. Nobakht, M.; Sakhaeifar, M.S. Dynamic modulus and phase angle prediction of laboratory aged asphalt mixtures. Constr. Build. Mater. 2018, 190, 740-751. [CrossRef]

41. Zadshir, M.; Hosseinnezhad, S.; Fini, E.H. Deagglomeration of oxidized asphaltenes as a measure of true rejuvenation for severely aged asphalt binder. Constr. Build. Mater. 2019, 209, 416-424. [CrossRef]

42. Moraes, R.; Bahia, H.U. Effect of mineral filler on changes in molecular size distribution of asphalts during oxidative ageing. Road Mater. Pavement Des. 2015, 16, 55-72. [CrossRef]

43. Smith, B.T.; Howard, I.L. Comparing Laboratory Conditioning Protocols to Longer-Term Aging of Asphalt Mixtures in the Southeast United States. J. Mater. Civ. Eng. 2019, 31, 04018346. [CrossRef]

44. Shi, P.; Li, X.; Shen, J. Nonlinear modelling of selected micro- and macro-properties of weathered asphalt mixtures. Constr. Build. Mater. 2020, 253, 119097. [CrossRef]

45. INVIAS-Instituto Nacional de Vías. Especificaciones Generales de Construcción de Carreteras; INVIAS: Bogotá, Colombia, 2020.

46. AASHTO. Standard Method of Test for Resistance to Plastic Flow of Bituminous Mixtures Using Marshall Apparatus; AASHTO T 245; AASHTO: Washington, DC, USA, 2015.

47. AASHTO. Standard Method of Test for Resistance of Compacted Asphalt Mixtures to Moisture-Induced Damage; AASHTO T 283; AASHTO: Washington, DC, USA, 2014.

48. ASTM. Standard Test Method for Indirect Tension Test for Resilient Modulus of Bituminous Mixtures; ASTM D4143; ASTM: West Conshohocken, PA, USA, 1995.

49. BSI (British Standards Institution). Bituminous Mixtures Test Methods for Hot Mix Asphalt. Part 25: Cyclic Compression Test; BS EN 12697-25; BSI: London, UK, 2004.

50. BSI (British Standards Institution). Bituminous Mixtures Test Methods for Hot Mix Asphalt. Part 24: Resistance to Fatigue; BS EN 12697-24; BSI: London, UK, 2005.

51. Doyle, J.; Howard, I. Characterization of Dense-Graded Asphalt with the Cantabro Test. J. Test. Evaluation 2014, 44. [CrossRef]

52. Cox, B.C.; Smith, B.T.; Howard, I.L.; James, R.S. State of Knowledge for Cantabro Testing of Dense Graded Asphalt. J. Mater. Civ. Eng. 2017, 29, 04017174. [CrossRef]

53. Hou, X.; Xiao, F.; Wang, J.; Amirkhanian, S. Identification of asphalt aging characterization by spectrophotometry technique. Fuel 2018, 226, 230-239. [CrossRef]

54. Teltayev, B.; Radovskiy, B. Predicting thermal cracking of asphalt pavements from bitumen and mix properties. Road Mater. Pavement Des. 2017, 19, 1832-1847. [CrossRef]

55. Ezzat, E.N.; Abed, A.H. The influence of using hybrid polymers, aggregate gradation and fillers on moisture sensitivity of asphaltic mixtures. Mater. Today: Proc. 2019, 20, 493-498. [CrossRef] 
56. Abo-Qudais, S.; Al-Shweily, H. Effect of aggregate properties on asphalt mixtures stripping and creep behavior. Constr. Build. Mater. 2007, 21, 1886-1898. [CrossRef]

57. Mirzababaei, P. Effect of zycotherm on moisture susceptibility of Warm Mix Asphalt mixtures prepared with different aggregate types and gradations. Constr. Build. Mater. 2016, 116, 403-412. [CrossRef]

58. Guo, F.; Pei, J.; Zhang, J.; Xue, B.; Sun, G.; Li, R. Study on the adhesion property between asphalt binder and aggregate: A state-of-the-art review. Constr. Build. Mater. 2020, 256, 119474. [CrossRef]

59. Nobakht, M.; Zhang, D.; Sakhaeifar, M.S.; Lytton, R.L. Characterization of the adhesive and cohesive moisture damage for asphalt concrete. Constr. Build. Mater. 2020, 247, 118616. [CrossRef]

60. Omar, H.A.; Yusoff, N.I.; Mubaraki, M.; Ceylan, H. Effects of moisture damage on asphalt mixtures. J. Traffic Transp. Eng. 2020, 7, 600-628. [CrossRef]

61. Diab, A.; Enieb, M.; Singh, D. Influence of aging on properties of polymer-modified asphalt. Constr. Build. Mater. 2018, 196, 54-65. [CrossRef]

62. Cao, W.; Wang, Y.; Wang, C. Fatigue characterization of bio-modified asphalt binders under various laboratory aging conditions. Constr. Build. Mater. 2019, 208, 686-696. [CrossRef]

63. Mousavi, M.; Pahlavan, F.; Oldham, D.J.; Hosseinnezhad, S.; Fini, E.H. Multiscale Investigation of Oxidative Aging in Biomodified Asphalt Binder. J. Phys. Chem. C 2016, 120, 17224-17233. [CrossRef]

64. Mastrofini, D.; Scarsella, M. The application of rheology to the evaluation of bitumen ageing. Fuel 2000, 79, 1005-1015. [CrossRef]

65. Aguiar-Moya, J.P.; Salazar-Delgado, J.; García, A.; Baldi-Sevilla, A.; Bonilla-Mora, V.; Loría-Salazar, L.G. Effect of ageing on micromechanical properties of bitumen by means of atomic force microscopy. Road Mater. Pavement Des. 2017, 18, 203-215. [CrossRef]

66. Yin, F.; Arámbula-Mercado, E.; Martin, A.E.; Newcomb, D.; Tran, N. Long-term ageing of asphalt mixtures. Road Mater. Pavement Des. 2017, 18, 1-26. [CrossRef]

67. Wen, Y.; Wang, Y. Effect of Oxidative Aging on Dynamic Modulus of Hot-Mix Asphalt Mixtures. J. Mater. Civ. Eng. 2019, 31, 04018348. [CrossRef]

68. Lira, B.; Ekblad, J.; Lundström, R. Evaluation of asphalt rutting based on mixture aggregate gradation. Road Mater. Pavement Des. 2019, 22, 1160-1177. [CrossRef]

69. De Farias, M.M.; Sinisterra, F.Q.; Quintana, H.A.R. Behavior of a hot mix asphalt made with recycled concrete aggregate and crumb rubber. Can. J. Civ. Eng. 2019, 46, 544-551. [CrossRef]

70. Rondón, H.A.; Reyes, F.A. Pavimentos-Materiales, Construcción y Diseño [Pavements: Materials, Construction and Design], 1th ed.; Editorial ECOE: Bogotá, Colombia, 2015.

71. Rondón-Quintana, H.A.; Ruge-Cárdenas, J.C.; Bastidas-Martínez, J.G.; Velandia-Castelblanco, M.Y.; de Farias, M.M. Use of Thermally Treated Bentonite as Filler in Hot Mix Asphalt. J. Mater. Civ. Eng. 2020, 32, 04020070. [CrossRef]

72. Bharath, G.; Reddy, K.S.; Tandon, V.; Reddy, M.A. Aggregate gradation effect on the fatigue performance of recycled asphalt mixtures. Road Mater. Pavement Des. 2019, 22, 165-184. [CrossRef]

73. Rahmani, E.; Darabi, M.K.; Little, D.N.; Masad, E.A. Constitutive modeling of coupled aging-viscoelastic response of asphalt concrete. Constr. Build. Mater. 2017, 131, 1-15. [CrossRef]

74. Moghaddam, T.B.; Baaj, H. The use of rejuvenating agents in production of recycled hot mix asphalt: A systematic review. Constr. Build. Mater. 2016, 114, 805-816. [CrossRef]

75. Zhang, H.; Gong, M.; Zhang, G.; Yang, B. Analysis of asphalt durability based on inherent and improved performance. Constr. Build. Mater. 2018, 181, 12-26. [CrossRef]

76. Ling, M.; Luo, X.; Chen, Y.; Hu, S.; Lytton, R.L. A calibrated mechanics-based model for top-down cracking of asphalt pavements Constr. Build. Mater. 2019, 208, 102-112. [CrossRef]

77. Luo, X.; Gu, F.; Ling, M.; Lytton, R.L. Review of mechanistic-empirical modeling of top-down cracking in asphalt pavements. Constr. Build. Mater. 2018, 191, 1053-1070. [CrossRef]

78. Wu, J.; Han, W.; Airey, G.; Yusoff, N.I. The influence of mineral aggregates on bitumen ageing. Int. J. Pavement Res. Technol. 2014, 7, 115-123.

79. Gamarra, A.; Ossa, E.A. Thermo-oxidative aging of bitumen. Int. J. Pavement Eng. 2018, 19, 641-650. [CrossRef]

80. Zhu, Z.; Singhvi, P.; Espinoza-Luque, A.F.; Ozer, H.; Al-Qadi, I.L. Influence of mix design parameters on asphalt concrete aging rate using I-FIT specimens. Constr. Build. Mater. 2018, 200, 181-187. [CrossRef] 